\title{
Synergistic antineoplastic effect of DLC1 tumor suppressor protein and histone deacetylase inhibitor, suberoylanilide hydroxamic acid (SAHA), on prostate and liver cancer cells: Perspectives for therapeutics
}

\author{
XIAOLING ZHOU, XU-YU YANG and NICHOLAS C. POPESCU \\ Laboratory of Experimental Carcinogenesis, Center for Cancer Research, National Cancer Institute, \\ National Institutes of Health, Bethesda, MD 20892, USA
}

Received November 11, 2009; Accepted December 14, 2009

DOI: 10.3892/ijo_00000580

\begin{abstract}
Inactivation of tumor suppressor genes is a major contributing alteration in the initiation or progression of cancer. The human tumor suppressor gene DLC1 (deleted in liver cancer 1) is frequently downregulated or silenced in multiple cancers, predominantly by epigenetic mechanisms. With the current considerable interest and progress in epigenetic therapy, a number of promising antineoplastic agents, particularly histone deacetylase (HDAC) inhibitors, have been developed and used successfully in clinical trials. Both DLC1 and HDAC inhibitors exert antineoplastic functions, and their combined action could be exploited for a more effective cancer therapy. To evaluate the potential benefits of this approach, we examined the antineoplastic effects of adenoviral (Ad)DLC1-mediated transduction and exposure to suberoylanilide hydroxamic acid (SAHA), a powerful HDAC inhibitor, in two human cancer cell lines that lack intrinsic DLC1 expression, $22 \mathrm{Rv} 1$ prostate cancer cells and $7703 \mathrm{~K}$ human hepatocellular carcinoma cells. Consistent with the oncosuppressive function of DLC1 in several cancers, including prostate and liver cancer, transduction of $22 \mathrm{Rv} 1$ and $7703 \mathrm{~K}$ cells with an Ad-DLC1 expression vector resulted in alterations of cell morphology, induction of apoptosis, and inhibition of cell proliferation, migration, and anchorage-independent growth. A low concentration of SAHA $(5 \mu \mathrm{M})$ efficiently restored the expression of DLC1 in 22Rv1 cells that lack DLC1 expression due to histone deacetylation but had a minimal effect in $7703 \mathrm{~K}$ cells in which silencing of the DLC1 gene is due mainly to promoter hypermethylation. Regardless of the epigenetic mechanism of DLC1 inactivation, SAHA treatment of DLC1-
\end{abstract}

Correspondence to: Dr N.C. Popescu, Laboratory of Experimental Carcinogenesis, National Cancer Institute, 37 Convent Drive, MSC 4262, Bethesda, MD 20892-4262, USA

E-mail: popescun@mail.nih.gov

Key words: DLC1, tumor suppressor gene, SAHA, apoptosis, cell proliferation, tumorigenicity, prostate cancer cells, liver cancer cells transduced cells had a synergistic inhibitory effect on tumor cell proliferation and tumorigenesis in both cell lines. In $22 \mathrm{Rv} 1$ cells, this combination regimen nearly abolished the formation of colonies in semisolid media as a measure of tumorigenicity in vitro. Current in vitro results validate this protocol as a potentially new therapeutic option in certain cancers.

\section{Introduction}

The DLC1 gene that encodes a Rho GTPase-activating protein is an authentic tumor-suppressor gene in several common cancers (1-3). Loss of DLC1 expression is a frequent mechanism for activation of Rho GTPases, key mediators of human oncogenesis (4). In contrast with the early observation that mutations in the coding region of DLC1 are infrequent in human cancers, recent genomewide sequencing analyses of prostate, colon, and pancreatic cancers have identified missense mutation of DLC1 $(5,6)$. Similarly, new data show that the incidence of DLC1 deletions in liver, lung, and breast tumors is higher than well-known tumor suppressor genes (2). Although genetic alterations are major contributors to deregulation of the DLC1 gene, most commonly silencing or downregulation of DLC1 in solid tumors and hematological malignancies is mediated by epigenetic mechanisms. $\mathrm{CpG}$ island hypermethylation of DLC1 was reported in a high proportion of epithelial tumors, including 75-90\% of carcinomas of the lung, breast, ovary, and kidney, and as high as $93 \%$ of non-Hodgkin's lymphomas (reviewed in ref. 3). Given the high frequency of genetic and epigenetic alterations, DLC1 is listed 10th among the top 50 genes implicated in multiple cancers (7). Cells derived from different types of cancer, such as breast, lung, liver, ovary, prostate, and multiple myeloma (MM), are highly sensitive to reactivation of DLC1 function. Transcriptional reactivation of DLC1 in human tumor cells with disabled DLC1 suppresses proliferation and migration, induces apoptosis in vitro, and inhibits both in vivo tumorigenicity and the development of metastases (reviewed in ref. 3).

Prostate cancer is among various types of cancer exhibiting recurrent downregulation or inactivation of DLC1 partially due to epigenetic mechanisms. Promoter methylation of DLC1 was detected in nearly $50 \%$ of prostate carcinomas and 
$70 \%$ of benign prostatic hyperplasias (BPHs), but not in normal prostatic tissues. Methylation of DLC1 correlated with the age of prostate carcinoma patients and with prostate-specific antigen blood levels in BPH patients (8). Histone deacetylation is also an important component of DLC1 silencing, as demonstrated with PC-3, LNCaP, and 22Rv1 prostate carcinoma cell lines that are DLC1-negative or express a low level of DLC1 transcripts. Treatment with trichostatin-A (TSA), a widely used HDAC inhibitor restored DLC1 expression in 22Rv1 cells and, to a lesser extent, in LNCap, but was ineffective in PC-3 cells (8). In contrast with other prostate carcinoma cells, Ad-DLC1-mediated transduction of PC-3 cells failed to induce apoptosis (9). These observations correlate strikingly with the sensitivity of prostate tumor cells to the induction of apoptosis by suberoylanilide hydroxamic acid (SAHA) (vorinostat), another potent HDAC inhibitor (10). Treatment of PC-3 cells with SAHA was ineffective in inducing apoptosis compared with other prostate carcinoma cell lines. This refractory response to different factors, a chemical compound and a tumor-suppressor protein, was related to the high level of the antiapoptotic protein Bcl-2, as PC-3 cells rendered sensitive to SAHA or DLC1 induced apoptosis after treatment with the Bcl-2 inhibitor HA14-1 $(9,10)$.

Given the ability of HDAC inhibitors to suppress cancer cell proliferation, to induce apoptosis in vitro and in vivo, and to restore the expression of DLC1 in tumor cells with disabled DLC1, we decided to evaluate the combined effects of DLC1 transduction and exposure to SAHA on prostate and liver tumor cells. We selected the $22 \mathrm{Rv} 1$ prostate carcinoma cell line for several reasons. In 22Rv1 cells, inactivation of DLC1 was mediated primarily by histone deacetylation, and these cells are highly responsive to TSA-induced transcriptional reactivation of the gene. Also, tumors developed in nude mice by inoculation of $22 \mathrm{Rv} 1$ cells have been used previously to test SAHA effects in vivo (11). Because none of the small number of existing prostate carcinoma cell lines exhibit inactivation of DLC 1 mainly associated with promoter methylation, for comparative analysis, we used 7703K, a hepatocellular carcinoma (HCC) cell line lacking endogenous DLC1 expression that re-expresses mRNA after treatment with 5-aza-2'-deoxycytidine (5-azadC) (12). To determine whether SAHA cooperates with the function of DLC1, we examined the effect of SAHA in Ad-DLC1-transduced cells and showed that their combined action elicits a synergistic antineoplastic effect in prostate and liver cancer cells.

\section{Materials and methods}

Cell lines and culture conditions. The human prostate carcinoma cell line 22Rv1 was purchased from American Type Culture Collection (Manassas, VA, USA) and was cultured in RPMI-1640 (Invitrogen, San Diego, CA, USA), and the HCC cell line 7703K from our laboratory stock was cultured in DMEM/F12. Both media were supplemented with $10 \%(\mathrm{v} / \mathrm{v})$ fetal calf serum and were maintained at $37^{\circ} \mathrm{C}$ in a humidified incubator containing $5 \% \mathrm{CO}_{2}$.

Chemicals and treatments. SAHA was provided by Aton Pharma (Tarrytown, NY, USA) under an agreement with the National Cancer Institute. A stock solution of $5 \mathrm{mM}$ was prepared in DMSO, and in all experiments, an equivalent volume of DMSO was added to the culture medium of control cells. Treatments included $5 \mu \mathrm{M}$ SAHA or DMSO for 24,48 , or $72 \mathrm{~h}$ based on the experimental design.

Real-time PCR analysis. Real-time polymerase chain reaction (PCR) analysis of DLC1 mRNA was performed as previously described using an ABI PRISM 7900 sequence detection system under universal cycling conditions (Perkin-Elmer Applied Biosystems, Foster City, CA, USA) (8). The amount of DLC1 mRNA was normalized by that of glyceraldehyde3-phosphate dehydrogenase (GAPDH) mRNA. The 2- $\Delta \Delta \mathrm{Ct}$ method was used to calculate the relative fold difference of DLC1 mRNA.

Adenovirus infection. The pAd/CMV/V5-DEST expression vectors (Invitrogen) with human DLC1 and LacZ cDNA inserts were prepared and used for production of adenovirus as previously described in detail (9). 22Rv1 and $7703 \mathrm{~K}$ cells were seeded at $2 \times 10^{6}$ cells $/ 100 \mathrm{~mm}$ dish $24 \mathrm{~h}$ before infection, and adenovirus for expression of DLC1 (Ad-DLC1) or LacZ (Ad-LacZ) were added at MOIs 100 in $8 \mathrm{ml}$ of medium. After $24 \mathrm{~h}$ post infection, the virus-containing medium was removed and the cells were cultured in a complete fresh medium for another $24 \mathrm{~h}$ before use in experiments.

Luciferase assay and DLC1 promoter activity. 22Rv1 and $7703 \mathrm{~K}$ cells were transfected with the DLC1 promoterluciferase construct (kindly provided by Dr Yung-Jue Bang from Seoul National University College of Medicine, Korea), using Lipofectamine 2000 (Invitrogen). Twenty-four hours post transfection, cells were treated with $5 \mu \mathrm{M}$ SAHA, or DMSO as control, for an additional $24 \mathrm{~h}$. The DLC1 promoter activities of $22 \mathrm{Rv} 1$ and $7703 \mathrm{~K}$ cells were evaluated with the britelite $^{\mathrm{TM}}$ plus luciferase assay kit (Perkin-Elmer, Waltham, MA, USA) according to the manufacturer's instructions. Luciferase activities were measured using a Wallac plate reader.

Cell morphology, proliferation, and viability. 22Rv1/AdDLC1, 22Rv1/Ad-LacZ, 7703K/Ad-DLC1, and 7703K/AdLacZ cells infected with adenovirus as described above were seeded in 6-well plates at $5 \times 10^{4}$ cells per well. After $24 \mathrm{~h}$, $5 \mu \mathrm{M}$ SAHA or DMSO were added to the cultures, and the medium was changed every other day. On each of 5 days after chemical treatment, one well of each culture was examined and photographed with a Nikon Eclipse TE2000U inverted microscope with twin CCD cameras for recording morphological changes. Cells in another well of each culture were collected after trypsinization, and cell number and viability were determined by trypan blue exclusion with the use of a cellometer (Nexcelom Bioscience, Lawrence, MA, USA).

Caspase-3 activity. Ad-DLC1- and Ad-LacZ-transduced 22Rv1 and $7703 \mathrm{~K}$ cells were cultured in 96-well plates with $5 \mu \mathrm{M}$ SAHA or DMSO for $24 \mathrm{~h}$. Caspase activity was determined with a Caspase-Glo 3/7 assay kit, according to the manufacturer's instructions (Promega Corp., Madison, WI, USA). Generation of luminescent signal (the number of relative light units, RLU), indicative of caspase- 3 activity, was measured 
with a Wallac multilabel plate reader (Perkin-Elmer, Waltham, MA, USA).

Cell invasion assay. The invasiveness of cells in vitro was determined $24 \mathrm{~h}$ after SAHA or DMSO treatment of Ad-DLC1 22Rv1 and 7703K and Ad-LacZ 22Rv1 and 7703K cells with an InnoCyte ${ }^{\mathrm{TM}}$ cell invasion assay kit (EMD Chemicals, Inc., Gibbstown, NJ, USA). A total of $2 \times 10^{5}$ cells were seeded in a serum-free medium into the upper compartment of the invasion chambers containing a membrane coated with a basement membrane matrix (pore size, $8 \mu \mathrm{m}$ ). The lower compartment of the chambers contained a complete medium. After incubation of the chambers for $24 \mathrm{~h}$ at $37^{\circ} \mathrm{C}$ under $5 \% \mathrm{CO}_{2}$, cells that had migrated to the bottom surface of the membrane were stained with a $500 \mu \mathrm{l}$ cell staining solution supplied with the kit for an additional 30-60-min incubation. Staining solution (200 $\mu \mathrm{l}$ ) containing the dislodged invasive cells was transferred to duplicate wells of a 96-well plate. The fluorescence was measured at an excitation wavelength of $485 \pm 10 \mathrm{~nm}$ and an emission wavelength of $520 \pm 10 \mathrm{~nm}$.

Assay of anchorage-independent cell growth. Colony formation in soft agar was evaluated with the use of a cell transformation detection assay kit (Chemicon International, Billerica, MA, USA). 22Rv1 and 7703K cells infected with Ad-LacZ or Ad-DLC1 and treated with SAHA or DMSO for $24 \mathrm{~h}$ were suspended in $0.35 \%$ low-melting-point agarose and were plated at a density of $2 \times 10^{4}$ per well on a layer of $0.8 \%$ agarose in 6-well culture plates according to the manufacturer's manual. The number of colonies with a diameter of $>100 \mu \mathrm{M}$ was counted after culture for 3 weeks.

Statistical analysis. All of the data represent three independent experiments. The significance of differences between means was determined by Student's t-test. A p $<0.05$ was considered statistically significant.

\section{Results}

SAHA-mediated restoration of DLC1 expression in 22Rv1 and $7703 \mathrm{~K}$ cells. The $22 \mathrm{Rv} 1$ and $7703 \mathrm{~K}$ tumor cell lines used in this study are DLC1-negative primarily due to histone deacetylation and promoter hypermethylation, respectively $(8,12)$. We first examined the effect of SAHA on DLC1 expression. As expected from the mechanism responsible for silencing of the DLC1 gene, exposure to SAHA efficiently restored DLC1 expression in 22Rv1 cells. Exposure of 22Rv1 cells to $5 \mu \mathrm{M}$ SAHA for 24 and $48 \mathrm{~h}$ resulted in an increased level of DLC1 expression of 30- and 55-fold, respectively. In $7703 \mathrm{~K}$ cells, the same concentration of SAHA resulted in only approximately a 3 -fold increase in DLC1 expression (Fig. 1).

Activation of DLC1 promoter by SAHA in Ad-DLC1-transduced cells. To determine whether the SAHA-mediated increase in DLC1 mRNA levels is regulated by activation of DLC1 promoter, $22 \mathrm{Rv} 1$ and $7703 \mathrm{~K}$ cells were transfected with the DLC1 promoter-luciferase construct (577/+117pGL3b) and cultured in the presence of $5 \mu \mathrm{M}$ SAHA for $24 \mathrm{~h}$ (13). In 22Rv1 cells, SAHA increased the activity of DLC1

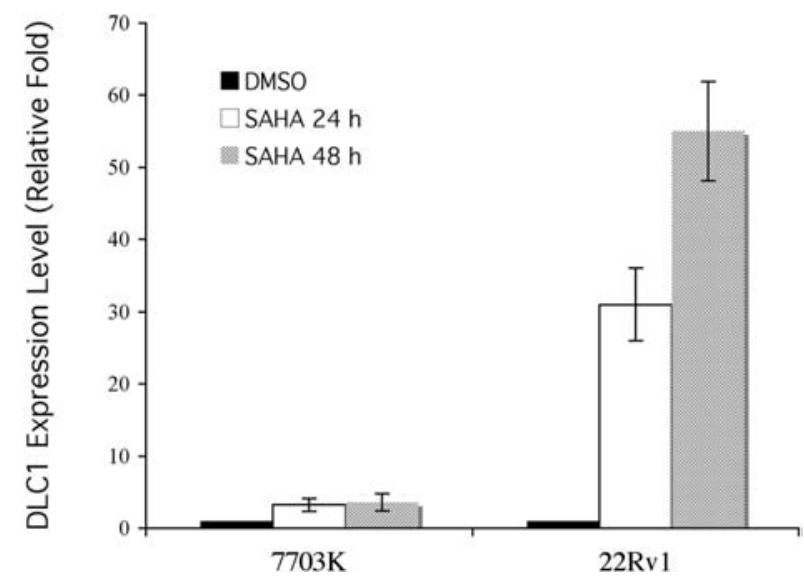

Figure 1. Induction of DLC1 expression in 22Rv1 and 7703K cells by SAHA. Real-time PCR analysis of DLC1 expression in 22Rv1 and 7703K cells 24 and $48 \mathrm{~h}$ after treatment with $5 \mu \mathrm{M}$ SAHA. Data are presented as the mean \pm SE of triplicate values from a typical experiment.

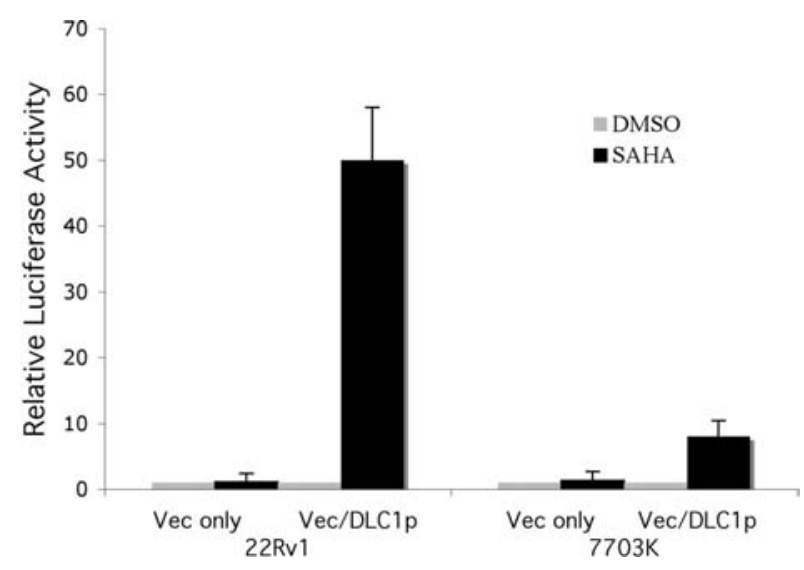

Figure 2. Activation of DLC1 promoters by SAHA. 22Rv1 and 7703K cells were transiently transfected with the empty reporter vector pGL3b (Vec only) or the DLC1 promoter-luciferase construct 577/+117-pGL3b (Vec/DLC1p) for $24 \mathrm{~h}$, followed by treatment with DMSO or $5 \mu \mathrm{M}$ SAHA for $24 \mathrm{~h}$. The DLC1 promoter activity was measured and indicated by relative luciferase activity. The data represent the combined results of three independent experiments.

promoter by 50 -fold (Fig. 2). Consistent with the low level of DLC1 expression induced by SAHA in $7703 \mathrm{~K}$ cells, there was only an eightfold increase in DLC1 promoter activity, suggesting that histone deacetylation also contributed to the transcriptional silencing of DLC1 in 7703K cells (Fig. 2).

Effects of SAHA on cell proliferation and viability. It has been well-documented that overexpression of DLC1 suppresses cell proliferation and tumorigenicity (reviewed in ref. 3). Cells transduced with Ad-DLC1 and Ad-LacZ controls were used to assess the effect of SAHA on cell proliferation and viability. Both DLC1 reexpression and treatment with SAHA inhibited 22Rv1 and 7703K cell growth and viability. SAHA treatment of Ad-DLC1-transduced cells was more effective than each taken separately in both cell lines. However, $22 \mathrm{Rv} 1$ cells were considerably more sensitive than $7703 \mathrm{~K}$ cells over a period of 5 days after exposure to $5 \mu \mathrm{M}$ SAHA (Fig. 3). 
A
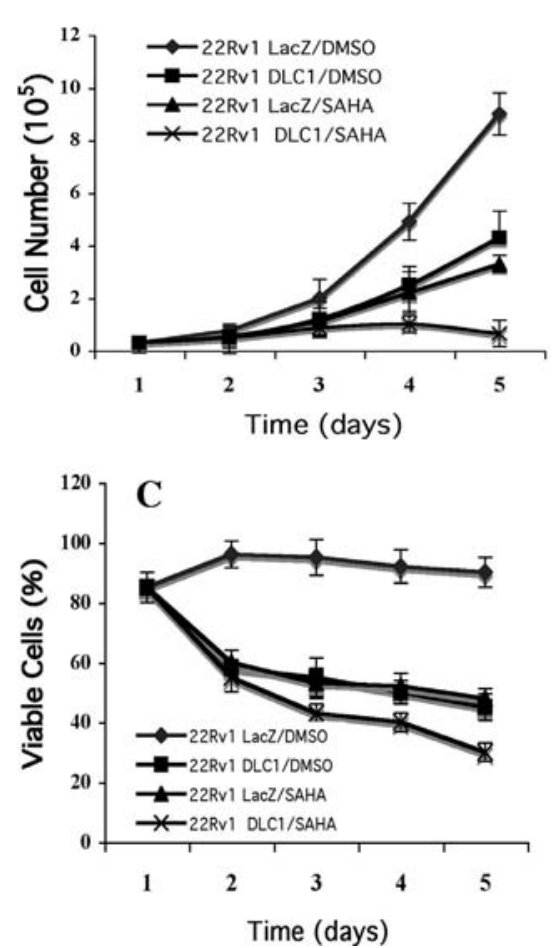

B

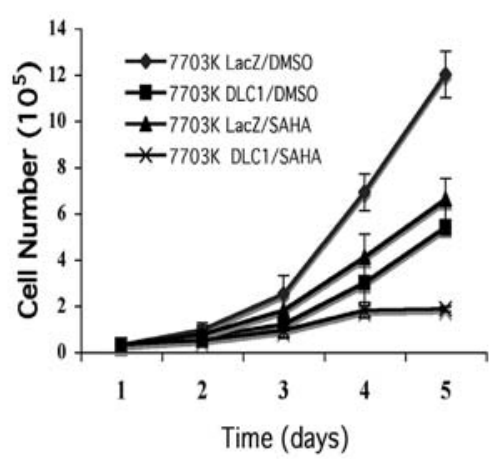

D

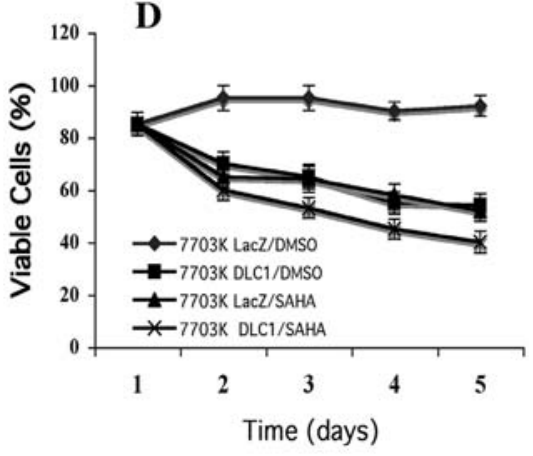

Figure 3. Reduction of cell proliferation and cell viability by SAHA in DLC1-transduced 22Rv1 and 7703K cells. Growth kinetics of 22Rv1 (A) and 7703K (B) cells during 5 days of SAHA treatment $(5 \mu \mathrm{M})$. Cell viability was evaluated by trypan blue staining over 5 days after SAHA addition to 22Rv1 (C) and 7703K (D) cells. Each condition was examined in triplicate; bars, \pm SE.

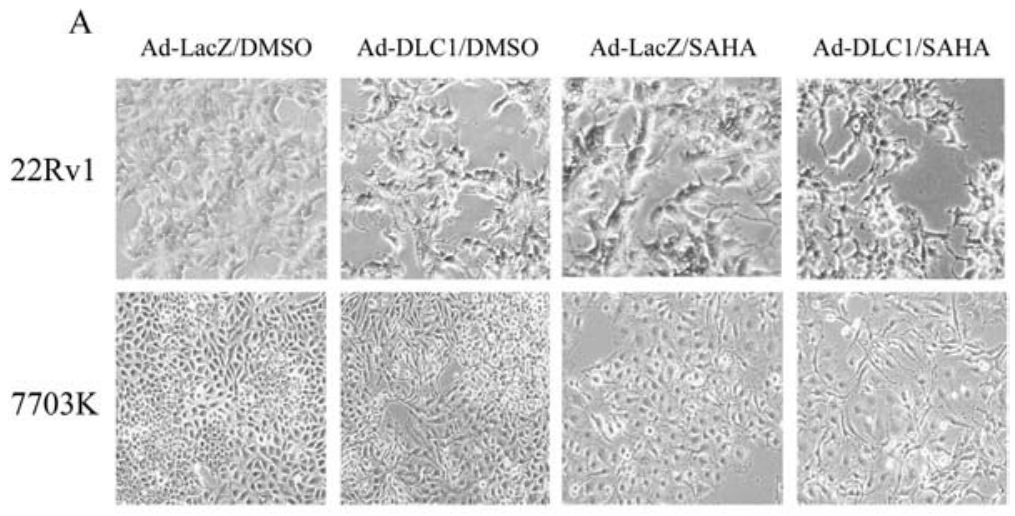

B

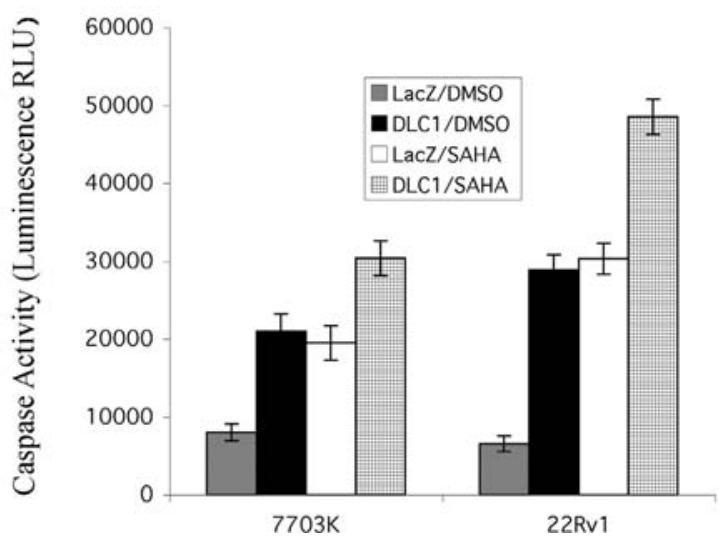

Figure 4. Alterations of cell morphology and activation of caspase activity induced by SAHA in DLC1-transduced cells. Microscopic images of 22Rv1 (A, upper row) and $7703 \mathrm{~K}$ (A, lower row) cells after $72 \mathrm{~h}$ of SAHA treatment. In addition to reduced cell density, cells from both cell lines showed loss of membrane attachment and cell shrinkage, especially in Ad-DLC1/SAHA groups. (B) Treatment with $5 \mu \mathrm{M}$ SAHA for $24 \mathrm{~h}$ in combination with DLC1 transduction increased caspase activity more than in SAHA and DLC1 alone. The data shown are the mean levels of caspase activity \pm SE from three independent experiments. 
A

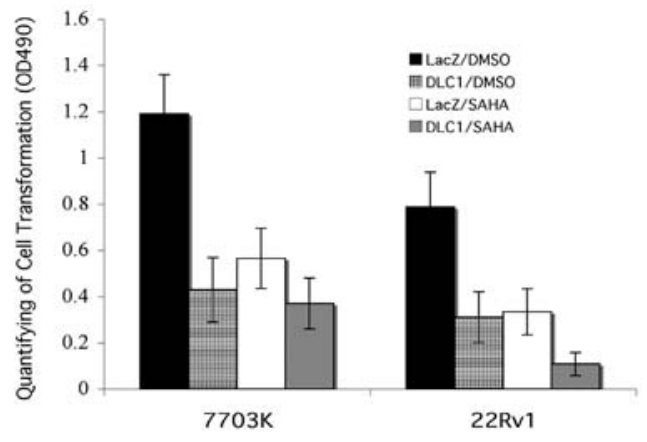

B LacZ/DMSO DLC1/DMSO LacZ/SAHA DLC1/SAHA

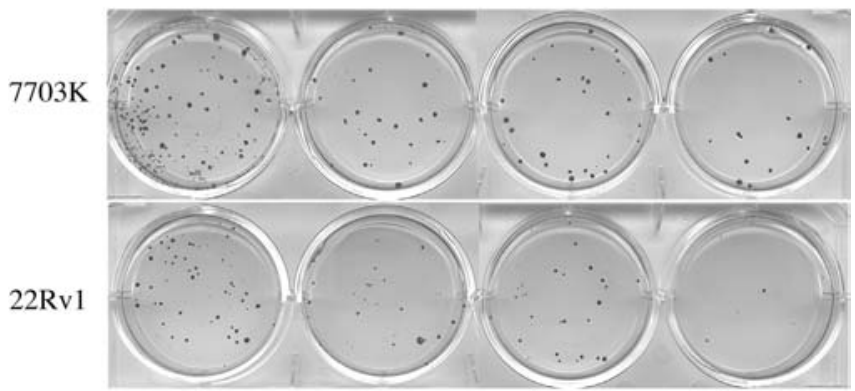

C

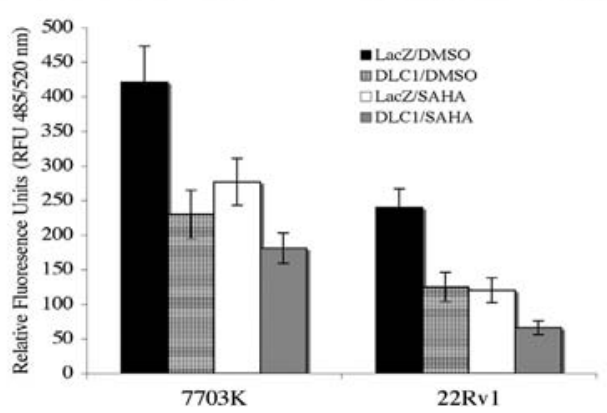

Figure 5. Inhibition of colony formation in soft agar and cell invasion by SAHA in DLC1-transduced cells. Ad-DLC1-transfected 7703K and 22Rv1 cells with or without SAHA treatment were assayed for the ability to form colonies during incubation in soft agar for 4 weeks (A and B). Data are expressed as the number of colonies per well and are the means \pm SE from three independent experiments. $7703 \mathrm{~K}$ and $22 \mathrm{Rv} 1$ cells that had migrated to the lower surface of the membrane were quantified by fluorescence and expressed as the means \pm SE from three independent experiments (C).

Alterations of cell morphology and activation of caspase-3 activity by SAHA. To determine whether the reduction in cell proliferation and viability is associated with morphological alterations and may reflect induction of apoptosis, we next examined changes in cell morphology and caspase- 3 activity in Ad-DLC1-transduced cells in the presence and absence of SAHA. Morphological alterations were observed in both $22 \mathrm{Rv} 1$ and $7703 \mathrm{~K}$ cells and became most noticeable $72 \mathrm{~h}$ after treatment with SAHA (Fig. 4A). These alterations consisted of cell blebbing, loss of membrane attachment, and shrinkage, all of which suggest apoptosis. Consistently, changes in cell morphology were more severe in SAHAtreated DLC1-transduced cells than when each was used separately (Fig. 4A). Activation of caspases is critical in the induction of apoptosis. Both DLC1 reactivation and HDAC inhibitors, including SAHA, activate caspases $(9,14,15)$. In SAHA-treated and DLC1-transduced cells, caspase-3 was activated (Fig. 4B). The caspase activity of 22Rv1 cells was increased 4.4- or 4.6-fold with SAHA or DLC1 alone, respectively, and $\sim 7$.4-fold with both SAHA and DLC1
(Fig. 4B). The relative increase in caspase activity was lower in $7703 \mathrm{~K}$ cells than in $22 \mathrm{Rv} 1$ cells; an increase of $2.4-$ or 2.6-fold resulted after treatment with SAHA and DLC1 transduction alone, respectively, and a 3.8-fold increase occurred when the two were combined (Fig. 4B).

Oncosuppressive effects of SAHA. 22Rv1 and 7703K cells infected with either Ad-DLC1 or Ad-LacZ and treated with SAHA or DMSO were examined for colony formation in soft agar and for cell invasion. Anchorage-independent growth, as assessed by the number and size of colonies formed in soft agar assays, was significantly more pronounced in the $22 \mathrm{Rv} 1$ cell line than in $7703 \mathrm{~K}$ cells (Fig. 5A and B). DLC1 expression and SAHA treatment inhibited the number of colonies by 61 and $42 \%$, respectively, in 22Rv1 cells and by 64 and $53 \%$ in $7703 \mathrm{~K}$ cells (Fig. 5A). The combination of DLC1 expression and SAHA treatment resulted in a reduction of colony formation by 86 and $69 \%$ in $22 \mathrm{Rv} 1$ and $7703 \mathrm{~K}$, respectively (Fig. 5A). To evaluate the effect of SAHA and DLC1 on cell invasion, transwell invasion assays were assessed (Fig. 5C). SAHA treatment or DLC1 transduction inhibited the invasiveness of $22 \mathrm{Rv} 1$ cells by 48 and $41 \%$, respectively, and that of $7703 \mathrm{~K}$ cells by 34 and $46 \%$. The invasiveness of 22Rv1 and 7703K DLC1-transduced cells treated with SAHA was reduced 73 and $57 \%$ (Fig. 5C).

\section{Discussion}

During the process of cancer development, the expression output of a variety of genes can be altered by mutations, amplifications, deletions, and epigenetic modifications consisting primarily of DNA methylation and histone acetylation/deacetylation modifications (16-18). Epigenetic changes are important in the initiation and progression of human neoplasia particularly by promoting silencing of tumor suppressor genes in many forms of cancer (19). In a recent report, current concepts and advances in the epigenetic control of tumor suppression are comprehensively covered and underline the contribution of DNA methylation and histone deacetylation to the complexity of gene regulation in oncogenesis (20). Unlike genetic changes, epigenetic alterations are reversible and thus provide a target for therapeutic interventions (21). Because DNA methyltransferase inhibitors and HDAC inhibitors have the distinct capacity to reactivate silenced tumor suppressor genes and to elicit antioncogenetic activities, a significant effort was directed in developing agents with therapeutic potential such as zebularine, a stable DNA cytosine DNA methylation inhibitor, and a number of HDAC inhibitors, including SAHA, which is already used in clinical trials for certain cancers (22-25).

Previous studies showed that TSA efficiently restores the expression of DLC1 in gastric and prostate cancer cells as well as in MM (26-28). Recently, a study providing clues for the mechanism responsible for the induction of DLC1 expression through HDAC-mediated chromatin modifications demonstrated that TSA activates DLC1 promoter in gastric cancer cells and that $\mathrm{Sp} 1$ binding sites are required for promoter activation (13).

In a preliminary attempt, we now show that SAHA significantly increased DLC1 promoter activity, particularly in 
prostate cancer cells with DLC1 silenced by histone deacetylation. Experiments are in progress to determine whether SAHA activates the DLC1 promoter through the same Sp1 binding sites or other elements of DLC1 promoter.

Current results show clearly that DLC1 re-expression and SAHA exposure synergistically inhibit in vitro growth of prostate and liver carcinoma cells. Experiments in immunocompromised mice are under way in our laboratory as a step toward clinical interventions. The inhibition of xenotransplanted prostate tumor growth in nude mice by SAHA underscores the importance of in vivo experiments (11). Very recently, a preclinical in vivo study demonstrated SAHAmediated prevention of brain metastasis of 231-BR cells, a brain trophic subline of MDA-MB-231 breast carcinoma cell line, in the absence of apoptosis by accumulation of doublestrand breaks and downregulation of $\operatorname{Rad52}$, a DNA repair gene (29). DLCl also was found to be downregulated in MDA-MB-231 breast cell populations that were highly metastatic to bone (30). Similarly, in two isogenic breast and prostate cancer sublines with diametrically opposite metastatic capabilities, DLC1 is downregulated in metastatic compared with nonmetastatic clones. Ad-DLC1-mediated transfer in metastastic clones inhibited cell proliferation and anchorage-independent growth in vitro and induced apoptosis or development of lung metastases in nude mice (9,31). Based on current results, SAHA may enhance the Ad-DLC1-mediated suppression of metastases. In other experiments, we found that transcriptional reactivation of DLC1 in breast and lung carcinoma cell lines prevented the development of tumors in nude mice, whereas in liver and prostate carcinoma lines, DLC1 re-expression resulted only in a reduction in the size and number of tumors $(9,14,32,33)$. DLC1 transduction in conjunction with continuous SAHA treatment could significantly enhance the inhibition or even abolish the tumor development in nude mice of tumor cells that are less sensitive to DLC1 activation.

Despite the successful anticancer effects of HDAC inhibitors, it is increasingly recognized that their combination with other therapeutic modalities will be required to optimize treatment efficacy (34). In clinical trials, patients with MM who relapsed responded well to combined treatment with SAHA and bortezomib, a proteasome inhibitor (25). Another powerful combination would consist of treatment with zebularine that is preferentially incorporated into DNA and targets cancer cells, in conjunction with SAHA (35). This combination regimen was highlighted among the most promising therapeutic options in tumors with low levels of endogenous DLC1 expression (36). Reactivation of several tumor suppressor genes, such as MLH1, p16 $6^{\mathrm{INK} 4}$, or maspin, requires both DNA methyltransferase and HDAC inhibitors $(20,37,38)$. In myelodysplastic syndrome, acute myeloid leukemia, and MM, optimal re-expression of epigenetically silenced genes, including DLC1, was achieved when application of DNA methyltransferase inhibitors was sequentially followed by histone deacetylase inhibitors $(28,39)$. Most likely, the sequential application of these agents is effective in prostate cancer because both epigenetic alterations contribute to the silencing of the DLC1 gene (8).

As stated earlier, studies with prostate cancer cells show that in certain cell lines, SAHA treatment or transduction with DLC1 induced apoptosis only after treatment with the Bcl-2 inhibitor HA14-1 $(9,10)$. These results suggest that DLC1 transfer, alone or in combination with other agents such as Bcl-2 inhibitors or SAHA, might prove effective in the treatment of metastatic aggressive prostate tumors. Furthermore, an antisense Bcl-2 oligonucleotide that depleted the mRNAs for several members of the $\mathrm{Bcl}$ family, including Bcl-2, induced apoptosis in PC-3 cells and enhanced their chemosensitivity to chemotherapeutic agents or radiation, thus demonstrating that a variety of combinations could influence antioncogenic response in certain cancers (28).

In conclusion, several combinatorial options might hold clinical promise as anticancer therapy in tumors with disabled DLC1. Given the overwhelming evidence that DLC1 is silenced by epigenetic mechanisms with staggering frequency in a considerable number of solid tumors and hematological cancers, the development of a tailored combined therapeutic strategy could be beneficial for many patients.

\section{Acknowledgements}

This work was supported by the Intramural Research Program of the National Cancer Institute, NIH. We would like to thank Drs Yung-Jue Bang and Tai Young Kim for providing the DLC1 promoter-luciferase construct and Dr Victoria Richon for helpful suggestions.

\section{References}

1. Yuan BZ, Miller MJ, Keck CL, Zimonjic D, Thorgeirsson SS and Popescu NC: Cloning, characterization, and chromosomal localization of a gene frequently deleted in human liver cancer (DLC-1) homologous to rat RhoGAP. Cancer Res 58: 2196-2199, 1998.

2. Xue W, Krasnitz A, Lucito R, Sordella R, Vanaelst L, Cordon-Cardo C, Singer S, Kuehnel F, Wigler M, Powers S, Zender L and Lowe SW: DLC-1 is a chromosome $8 \mathrm{p}$ tumor suppressor whose loss promotes hepatocellular carcinoma. Genes Dev 22: 1439-1444, 2008.

3. Durkin ME, Yuan BZ, Zhou X, Zimonjic DB, Lowy DR, Thorgeirsson SS and Popescu NC: DLC-1: a Rho GTPaseactivating protein and tumour suppressor. J Cell Mol Med 11: 1185-1207, 2007.

4. Sahai E and Marshall CJ: RHO-GTPases and cancer. Nat Rev Cancer 2: 133-142, 2002.

5. Liao YC, Shih YP and Lo SH: Mutations in the focal adhesion targeting region of deleted in liver cancer-1 attenuate their expression and function. Cancer Res 68: 7718-7722, 2008.

6. Jones S, Zhang X, Parsons DW, Lin JC, Leary RJ, Angenendt P, Mankoo P, Carter H, Kamiyama H, Jimeno A, Hong SM, Fu B, Lin MT, Calhoun ES, Kamiyama M, Walter K, Nikolskaya T, Nikolsky Y, Hartigan J, Smith DR, Hidalgo M, Leach SD, Klein AP, Jaffee EM, Goggins M, Maitra A, IacobuzioDonahue C, Eshleman JR, Kern SE, Hruban RH, Karchin R, Papadopoulos N, Parmigiani G, Vogelstein B, Velculescu VE and Kinzler KW: Core signaling pathways in human pancreatic cancers revealed by global genomic analyses. Science 321 : 1801-1806, 2008

7. Pihur V, Datta S and Datta S: Finding common genes in multiple cancer types through meta-analysis of microarray experiments: a rank aggregation approach. Genomics 92: 400403, 2008

8. Guan M, Zhou X, Soulitzis N, Spandidos DA and Popescu NC: Aberrant methylation and deacetylation of deleted in liver cancer-1 gene in prostate cancer: potential clinical applications. Clin Cancer Res 12: 1412-1419, 2006.

9. Guan M, Tripathi V, Zhou X and Popescu NC: Adenovirusmediated restoration of expression of the tumor suppressor gene DLC- 1 inhibits the proliferation and tumorigenicity of aggressive, androgen-independent human prostate cancer cell lines: prospects for gene therapy. Cancer Gene Ther 15: 371-381, 2008. 
10. Xu W, Ngo L, Perez G, Dokmanovic M and Marks PA: Intrinsic apoptotic and thioredoxin pathways in human prostate cancer cell response to histone deacetylase inhibitor. Proc Natl Acad Sci USA 103: 15540-15545, 2006.

11. Butler LM, Agus DB, Scher HI, Higgins B, Rose A, CordonCardo C, Thaler HT, Rifkind RA, Marks PA and Richon VM: Suberoylanilide hydroxamic acid, an inhibitor of histone deacetylase, suppresses the growth of prostate cancer cells in vitro and in vivo. Cancer Res 60: 5165-5170, 2000

12. Yuan BZ, Durkin ME and Popescu NC: Promoter hypermethylation of DLC-1, a candidate tumor suppressor gene, in several common human cancers. Cancer Genet Cytogenet 140: 113-117, 2003.

13. Kim TY, Kim IS, Jong HS, Lee JW, Kim TY, Jung M and Bang YJ: Transcriptional induction of DLC-1 gene through Sp1 sites by histone deacetylase inhibitors in gastric cancer cells. Exp Mol Med 40: 639-646, 2008.

14. Zhou X, Thorgeirsson SS and Popescu NC: Restoration of DLC-1 gene expression induces apoptosis and inhibits both cell growth and tumorigenicity in human hepatocellular carcinoma cells. Oncogene 23: 1308-1313, 2004

15. Carew JS, Giles FJ and Nawrocki ST: Histone deacetylase inhibitors: mechanisms of cell death and promise in combination cancer therapy. Cancer Lett 269: 7-17, 2008.

16. Bishop JM: The molecular genetics of cancer. Science 235: 305-311, 1987.

17. Hanahan D and Weinberg RA: The hallmarks of cancer. Cell 100: 57-70, 2000.

18. Jones PA and Baylin SB: The epigenomics of cancer. Cell 128: 683-692, 2007

19. Herman JG: Hypermethylation of tumor suppressor genes in cancer. Semin Cancer Biol 9: 359-367, 1999.

20. Palii SS and Robertson KD: Epigenetic control of tumor suppression. Crit Rev Eukaryot Gene Expr 17: 295-316, 2007.

21. Botrugno OA, Santoro F and Minucci S: Histone deacetylase inhibitors as a new weapon in the arsenal of differentiation therapies of cancer. Cancer Lett 280: 134-144, 2009.

22. Yoo CB, Cheng JC and Jones PA: Zebularine: a new drug for epigenetic therapy. Biochem Soc Trans 32: 910-912, 2004.

23. Minucci S and Pelicci PG: Histone deacetylase inhibitors and the promise of epigenetic (and more) treatments for cancer. Nat Rev Cancer 6: 38-51, 2006.

24. Batty N, Malouf GG and Issa JP: Histone deacetylase inhibitors as anti-neoplastic agents. Cancer Lett 280: 192-200, 2009.

25. Richon VM, Garcia-Vargas J and Hardwick JS: Development of vorinostat: current applications and future perspectives for cancer therapy. Cancer Lett 280: 201-210, 2009.

26. Kim TY, Jong HS, Song SH, Dimtchev A, Jeong SJ, Lee JW, Kim TY, Kim NK, Jung M and Bang YJ: Transcriptional silencing of the DLC-1 tumor suppressor gene by epigenetic mechanism in gastric cancer cells. Oncogene 22: 3943-3951, 2003.

27. Song YF, Xu R, Zhang XH, Chen BB, Chen Q, Chen YM and Xie Y: High-frequency promoter hypermethylation of the deleted in liver cancer-1 gene in multiple myeloma. J Clin Pathol 59: 947-951, 2006.
28. Ullmannova-Benson V, Guan M, Zhou X, Tripathi V, Yang XY, Zimonjic DB and Popescu NC: DLC-1 tumor suppressor gene inhibits migration and invasion of multiple myeloma cells through RhoA GTPase pathway. Leukemia 23: 383-390, 2009.

29. Palmieri D, Lockman PR, Thomas FC, Hua E, Herring J, Hargrave E, Johnson M, Flores N, Qian Y, Vega-Valle E, Taskar KS, Rudraraju V, Mittapalli RK, Gaasch JA, Bohn KA, Thorsheim HR, Liewehr DJ, Davis S, Reilly JF, Walker R, Bronder JL, Feigenbaum L, Steinberg SM, Camphausen K, Meltzer PS, Richon VM, Smith QR and Steeg PS: Vorinostat inhibits brain metastatic colonization in a model of triple-negative breast cancer and induces DNA double-strand breaks. Clin Cancer Res (In press).

30. Kang Y, Siegel PM, Shu W, Drobnjak M, Kakonen SM, Cordon-Cardo C, Guise TA and Massague J: A multigenic program mediating breast cancer metastasis to bone. Cancer Cell 3: 537-549, 2003.

31. Goodison S, Yuan J, Sloan D, Kim R, Li C, Popescu NC and Urquidi V: The RhoGAP protein DLC-1 functions as a metastasis suppressor in breast cancer cells. Cancer Res 65: 6042-6053, 2005.

32. Yuan BZ, Zhou X, Durkin ME, Zimonjic DB, Gumundsdottir K, Eyfjord JE, Thorgeirsson SS and Popescu NC: DLC-1 gene inhibits human breast cancer cell growth and in vivo tumorigenicity. Oncogene 22: 445-450, 2003.

33. Yuan B-Z, Jefferson AM, Baldwin KT, Thorgeirsson SS, Popescu NC and Reynolds SH: DLC-1 operates as a tumor suppressor gene in human and non-small cell lung carcinomas. Oncogene 23: 1405-1411, 2004.

34. Nolan L, Johnson PW, Ganesan A, Packham G and Crabb SJ: Will histone deacetylase inhibitors require combination with other agents to fulfill their therapeutic potential? Br J Cancer 99: 689-694, 2008.

35. Cheng JC, Yoo CB, Weisenberger DJ, Chuang J, Wozniak C, Liang G, Marquez VE, Greer S, Orntoft TF, Thykjaer T and Jones PA: Preferential response of cancer cells to zebularine. Cancer Cell 6: 151-158, 2004

36. Lahoz A and Hall A: DLC1: a significant GAP in the cancer genome. Genes Dev 22: 1724-1730, 2008.

37. Cameron EE, Bachman KE, Myohanen S, Herman JG and Baylin SB: Synergy of demethylation and histone deacetylase inhibition in the re-expression of genes silenced in cancer. Nat Genet 21: 103-107, 1999.

38. Maass N, Biallek M, Rosel F, Schem C, Ohike N, Zhang M, Jonat $\mathrm{W}$ and Nagasaki K: Hypermethylation and histone deacetylation lead to silencing of the maspin gene in human breast cancer. Biochem Biophys Res Commun 297: 125-128, 2002.

39. Gore SD, Baylin S, Sugar E, Carraway H, Miller CB, Carducci M, Grever M, Galm O, Dauses T, Karp JE, Rudek MA, Zhao M, Smith BD, Manning J, Jiemjit A, Dover G, Mays A, Zwiebel J, Murgo A, Weng LJ and Herman JG: Combined DNA methyltransferase and histone deacetylase inhibition in the treatment of myeloid neoplasms. Cancer Res 66: 6361-6369, 2006. 